\title{
Observation and Analysis of Neutron-Induced Single-Event Burnout in Silicon Power Diodes
}

\author{
Tomoyuki Shoji, Shuichi Nishida, Kimimori Hamada, and Hiroshi Tadano
}

\begin{abstract}
Annular microvoids formed by neutron-induced single-event burnout (SEB) in Si power diodes were observed by a slice-and-view technique. The axial symmetry of damage region reflects the spatially-isotropic thermal diffusion that occurred. Analytical formulae for the local rise in temperature during SEB were derived from the thermal diffusion equation. The local temperature was found to increase in direct proportion to the deposited energy, which was expressed as the time integration of the product of the applied voltage and the SEB current. This current is the result of charges generated by recoil ions and subsequent current-induced avalanche. The diameter of the damage region was estimated using the analytical formulae and the energy associated with Joule heating, which was calculated by TCAD device simulations, and was found to be comparable in size to the observed annular voids. The SEB current density was also calculated based on the simulated SEB current and the size of the damage region.
\end{abstract}

Index Terms - Single event burnout (SEB), white-neutron irradiation, annular microvoids, thermal diffusion equation, current-induced avalanche (CIA)

\section{INTRODUCTION}

$\mathrm{H}$ IGH ENERGY particles at sea level are produced by nuclear spallation reactions between cosmic rays and atmospheric nuclei. There is general agreement that $97 \%$ of these particles are white neutrons with a broad energy distribution [1]. Cosmic-ray-induced neutrons cause catastrophic failure in power devices in a stochastic manner [2]-[6]. The failure rate associated with single-event burnout (SEB) increases sharply with applied voltage when the voltage exceeds a certain threshold value. It is therefore crucial to optimize the SEB threshold voltage during the device design stage in order to achieve highly reliable devices and avoid chance failures.

There have been several numerical investigations of the SEB failure mechanism [7]-[15]. In addition, white-neutron irradiation experiments and transient thermal simulations have been performed to analyze the SEB triggering mechanism in

T. Shoji is with Toyota Central R\&D Labs., Inc., Nagakute, Aichi 480-1192, Japan, and Graduate School of Pure and Applied Sciences, University of Tsukuba, Tsukuba, Ibaraki 305-8573, Japan (e-mail: shoji@mosk.tytlabs.co.jp).

S. Nishida and K. Hamada are with Toyota Motor Corporation, Toyota, Aichi 470-0309, Japan (e-mail: shuichi_nishida@mail.toyota.co.jp; kimimori_hamada@mail.toyota.co.jp).

H. Tadano is with Graduate School of Pure and Applied Sciences, University of Tsukuba, Tsukuba, Ibaraki 305-8573, Japan (e-mail: tadano.hiroshi.fn@u.tsukuba.ac.jp). silicon ( $\mathrm{Si}$ ) and silicon carbide ( $\mathrm{SiC})$ power devices [16]-[25]. A nuclear reaction between individual incident neutrons and $\mathrm{Si}$ nuclei induces recoil ion formation, and electron-hole pairs are generated along the ion track. A highly localized current then flows through the power device, and local thermal destruction can occur if the voltage applied to the device is higher than the SEB threshold voltage.

Transient thermal simulations have been used to investigate the behavior of electron-hole pairs generated along the ion tracks in power devices under the influence of the applied voltage. The electrostatic potential adopts a funnel-like shape and the highly localized current results in an increase in the electron density in the vicinity of the $\mathrm{n}^{-}$drift region $/ \mathrm{n}^{+}$diffusion region interface [16], [18]-[20], [22]. This space charge effect leads to a shift of the peak electric field from the $\mathrm{p}^{-}$body region $/ \mathrm{n}^{-}$drift region interface to the $\mathrm{n}^{-}$drift region $/ \mathrm{n}^{+}$diffusion region interface. Consequently, the electric field distribution assumes a hammock-like shape along the ion track, which corresponds to a region of negative differential resistance (NDR) [26], [27]. Punch-through at the anode contact subsequently occurs with increasing current density, and this corresponds to a region of positive differential resistance (PDR) [26]. Therefore, the diode behaves locally like a resistor. It was clarified that the SEB mechanism in power diodes is thermal failure caused by local secondary breakdown. Moreover, it was shown to be possible to control the SEB threshold voltage by optimal choice of device parameters such as the drift region thickness [16]-[20].

In the present study, annular microvoids formed by neutron-induced SEB in Si power diodes were observed using a slice-and-view technique. In addition, analytical formulae for the local rise in temperature during SEB were derived from the thermal diffusion equation. The diameter of the damage region was then estimated using these formulae together with the energy associated with Joule heating, which was determined by technology computer aided design (TCAD) device simulations. The SEB current density was also estimated based on the simulated SEB current and the size of the damage region.

\section{ANALYSIS OF NEUTRON-INDUCED SEB USING A SLICE-AND-VIEW PROCEDURE}

In the present study, white-neutron irradiation of Si power diodes was carried out. A schematic diagram of the experimental test circuit is shown in Fig. 1. A voltage of $1050 \mathrm{~V}$, which is close to the SEB threshold, was applied between the cathode and anode during neutron irradiation. Fig. 2 shows the 
chip failure rate as a function of the applied voltage for $\mathrm{Si}$ power devices. The failure rate is seen to increase sharply at a particular voltage, which is defined as the SEB threshold voltage [20]. Transient device simulations were carried out to clarify the SEB triggering mechanism for Si diodes, and the results are shown in Fig. 3. The applied voltage was $1050 \mathrm{~V}$, and SEB was found to occur at this voltage. It can be seen that the aluminum surface remains at room temperature during the SEB event.

Fig. 4 shows a scanning electron microscopy (SEM) image of the photoemission region at the anode identified using backside photoemission microscopy. The surface of the Al electrode showed no damage due to SEB. Fig. 5 shows SEM images of the Si surface after Al etching. A crater with an elevated rim is seen to be present, which is thought to be associated with motion of molten Si from within the device to the surface. Fig. 6(a) shows slice-and-view observations using FIB. The SEM image is at $0.4 \mu \mathrm{m}$ depth from the Si surface. Two damage regions with a spacing of $2 \mu \mathrm{m}$ can be observed, one of these regions is indicated by a yellow rectangle. The $\mathrm{p}^{+}$ diffusion layers in the anode region were indicated by the blue rectangles as shown in Fig. 6(b). Transient thermal device simulations were carried out for the cross section indicated by the dashed red line connecting the two damage regions in Fig. 6(b). As shown in Fig. 6(d), hole current crowding occurs at the corners of the $\mathrm{p}^{+}$diffusion layers, with a spacing of $2 \mu \mathrm{m}$. Consequently, the lattice temperature rises at the two points shown in Fig. 6(e). Therefore, the two damage regions indicate traces that branched hole currents flowed into the two $\mathrm{p}^{+}$ diffusion patterns. Fig. 7 shows slice-and-view SEM images of the damage region indicated by the yellow rectangle in Fig. 6(a). A unique annular microvoid with a diameter of about $1 \mu \mathrm{m}$ was observed in the $\mathrm{p}^{-}$body region on the anode side, as shown in Figs. 7(a)-(c). The presence of this void suggests that the maximum lattice temperature in the device reached the melting point of Si due to the highly localized current caused by SEB. When this occurred, atoms in the melted region migrated to the device surface owing to thermal expansion of the Si. An annular void was then formed at the circumference of the damage region during the cooling process, and $\mathrm{Si}$ erupted above the device surface, as shown in Fig. 5(b). The axisymmetric shape of the void reflects the spatially isotropic thermal diffusion that occurred.

As shown in Fig. 7(d), the void was no longer observed at a depth of $1.4 \mu \mathrm{m}$ from the Si surface (inside the $\mathrm{p}^{-}$body region on the anode side). At a depth of $2.8 \mu \mathrm{m}$, a relatively straight crack was observed, as shown in Fig. 7(e). Furthermore, linear cracks were formed on both sides of the melt-solidification region located in the center of the damage region, as shown in Fig. 7(f). The cracks gradually began to disappear in deeper regions, as seen in Figs. 7(g)-(o), and were completely gone at a depth of $9.8 \mu \mathrm{m}$, as shown in Fig. 7(p). Typically, cracks in materials originate at edges and surfaces, and then propagate inwards. However, the cracks due to SEB are unique in shape and only form inside the device.

Fig. 8 shows an analysis of the annular void region using high-angle dark-field scanning transmission electron microscopy (HAADF-STEM) and energy dispersive X-ray spectroscopy (EDX). A voltage of $1023 \mathrm{~V}$, which is close to the SEB threshold, was applied to the sample during white-neutron irradiation, so that the chip failure rate due to SEB was a function of the applied voltage, as shown in Fig. 2.

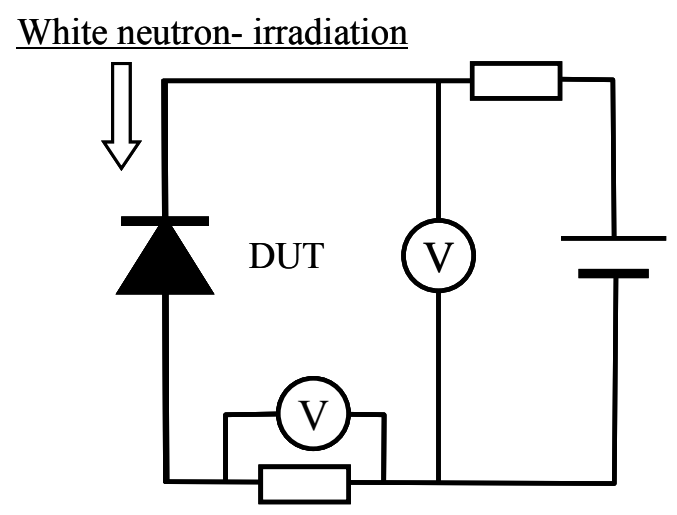

Fig. 1. Schematic diagram of experimental test circuit.

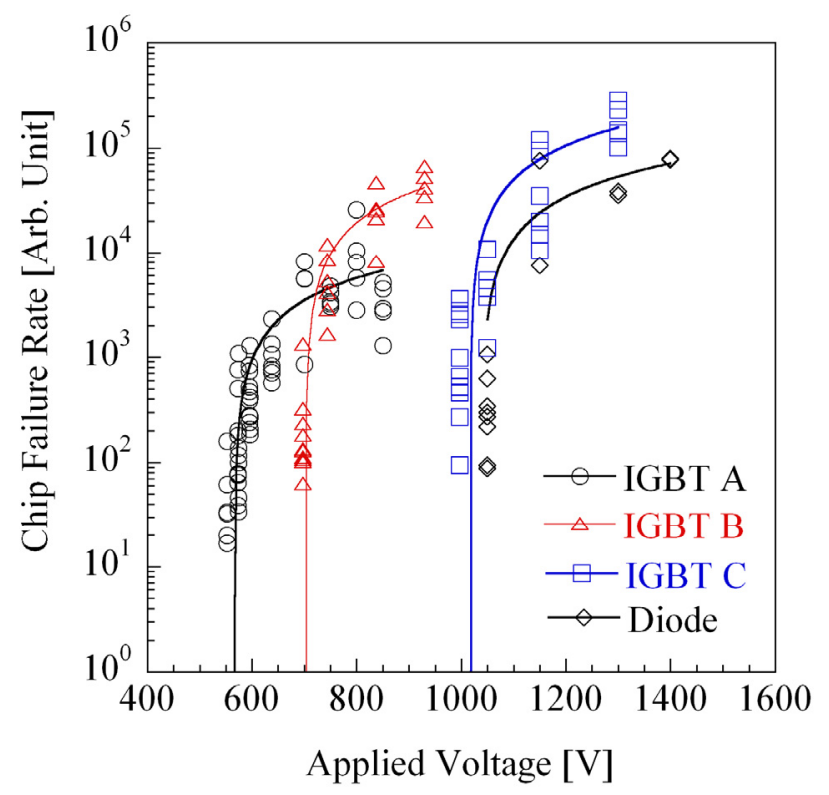

Fig. 2. Chip failure rate for Si power devices due to neutron-induced SEB as function of applied voltage ( $\mathrm{n}^{-}$drift thickness; IGBT C $>$IGBT B $>$IGBT A) [20].

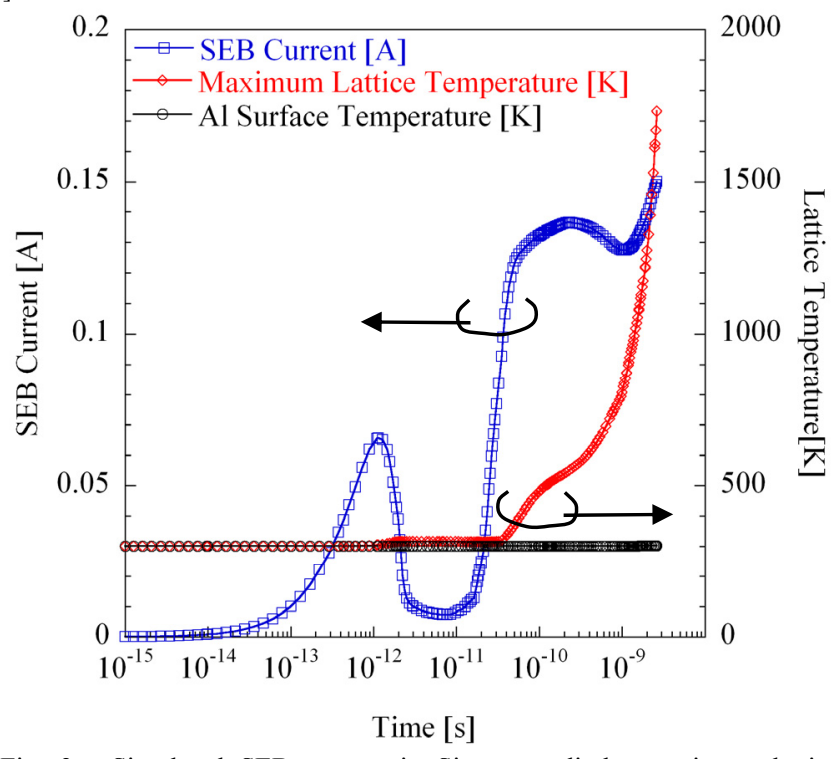

Fig. 3. Simulated SEB current in Si power diode, maximum lattice temperature, and maximum surface temperature of aluminum anode. 

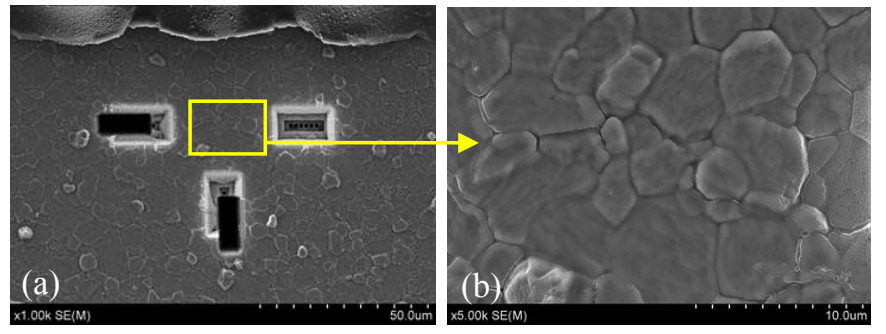

Fig. 4. SEM images of emission spot at anode identified using backside photoemission microscopy: (a) Low-magnification image and (b) high-magnification image.

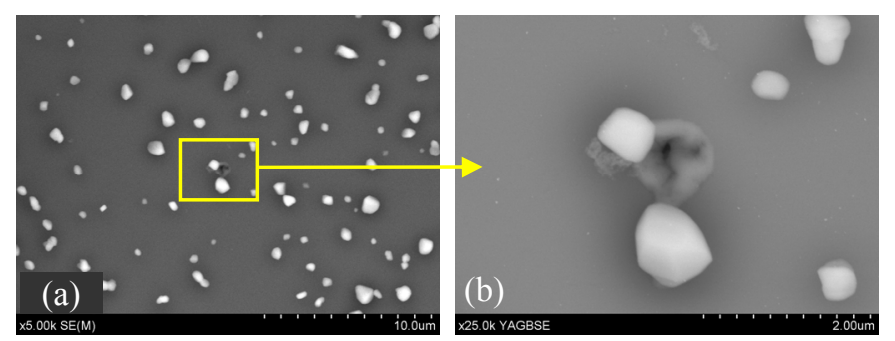

Fig. 5. SEM images of $\mathrm{Si}$ surface after aluminum etching: (a) Low-magnification image, and (b) high-magnification image.

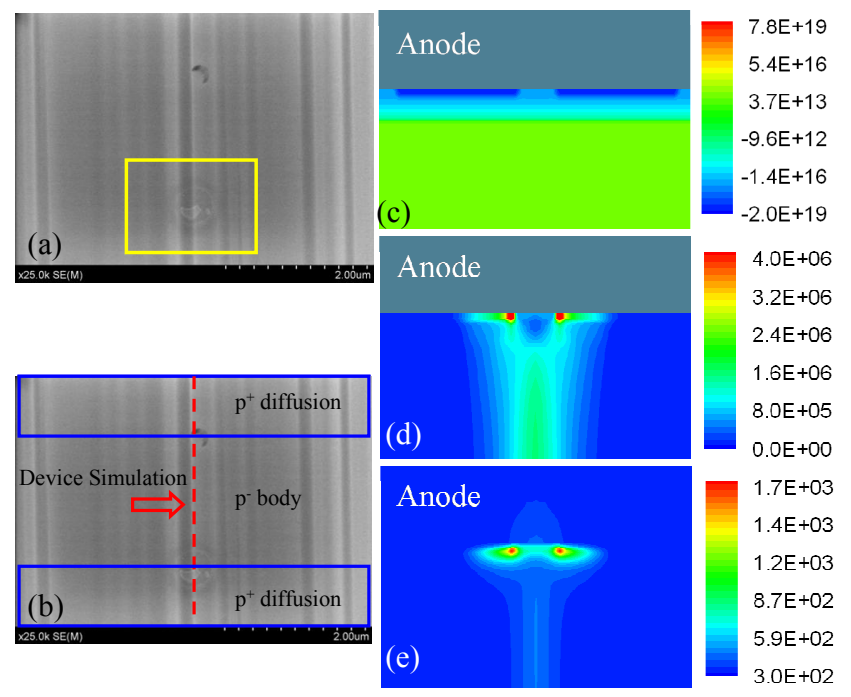

Fig. 6. Slice-and-view observations using FIB: SEM image at $0.4 \mu \mathrm{m}$ depth from the Si surface (a). Device simulation results at the broken red line shown in (b) when the maximum lattice temperature reaches the Si melting point: (c) doping profile $\left(/ \mathrm{cm}^{3}\right)$, (c) hole current density $\left(\mathrm{A} / \mathrm{cm}^{2}\right)$ and (e) lattice temperature $(\mathrm{K})$.

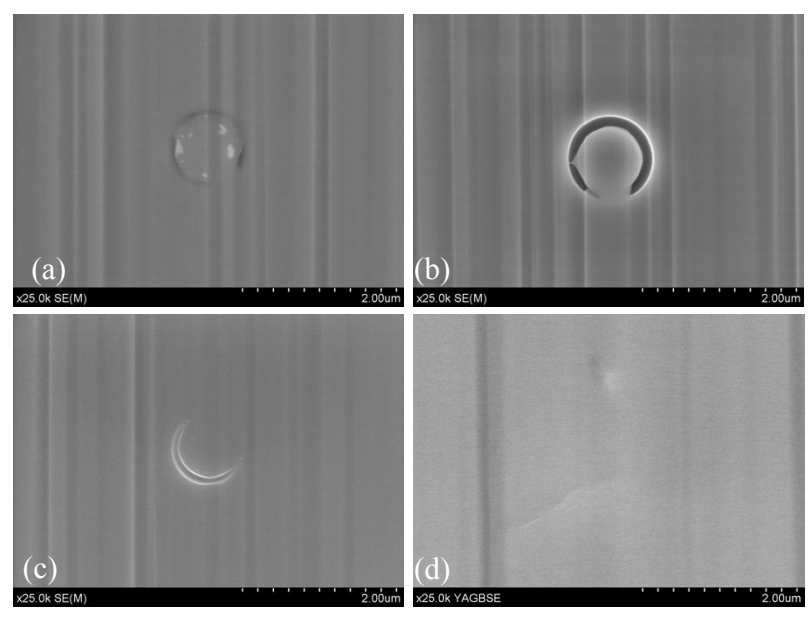

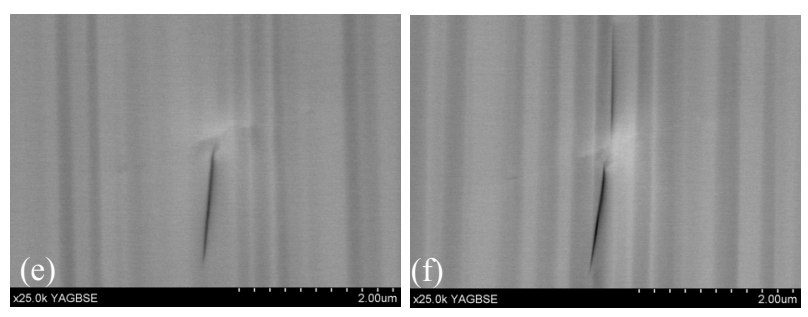
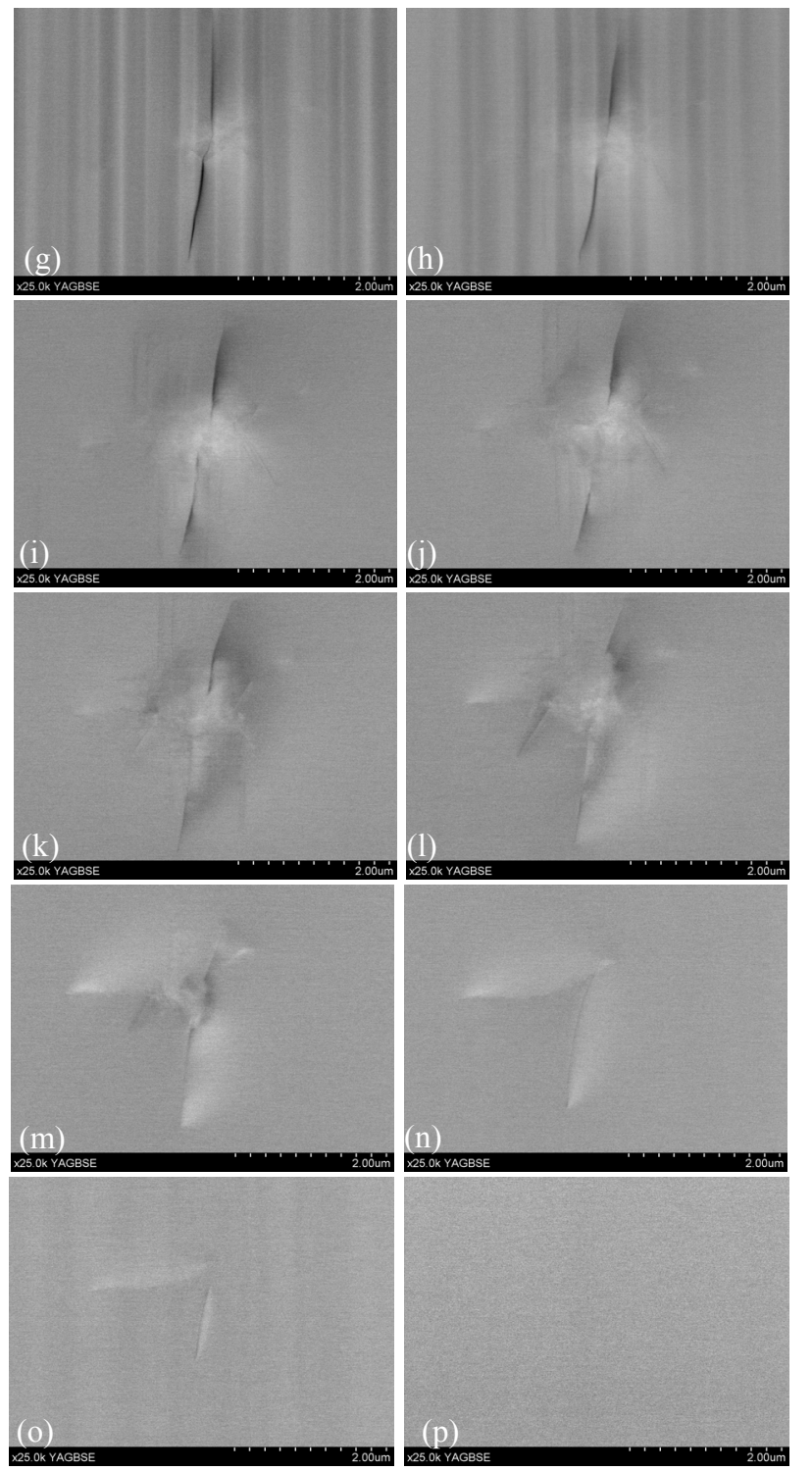

Fig. 7. Slice-and-view SEM images of damage region indicated by yellow rectangle in Fig. 6 (a):

(a) depth of $0.8 \mu \mathrm{m}$ from the Si surface (inside $\mathrm{p}^{-}$body on the anode side)

(b) depth of $1.0 \mu \mathrm{m}$ from the Si surface (inside $\mathrm{p}^{-}$body on the anode side)

(c) depth of $1.2 \mu \mathrm{m}$ from the Si surface (inside $\mathrm{p}^{-}$body on the anode side)

(d) depth of $1.4 \mu \mathrm{m}$ from the Si surface (inside $\mathrm{p}^{-}$body on the anode side)

(e) depth of $2.8 \mu \mathrm{m}$ from the Si surface (inside $\mathrm{n}^{-}$drift region)

(f) depth of $3.0 \mu \mathrm{m}$ from the Si surface (inside $\mathrm{n}^{-}$drift region)

(g) depth of $3.2 \mu \mathrm{m}$ from the Si surface (inside $\mathrm{n}^{-}$drift region)

(h) depth of $4.0 \mu \mathrm{m}$ from the Si surface (inside $\mathrm{n}^{-}$drift region)

(i) depth of $4.5 \mu \mathrm{m}$ from the $\mathrm{Si}$ surface (inside $\mathrm{n}^{-}$drift region)

(j) depth of $5.3 \mu \mathrm{m}$ from the $\mathrm{Si}$ surface (inside $\mathrm{n}^{-}$drift region)

(k) depth of $5.8 \mu \mathrm{m}$ from the $\mathrm{Si}$ surface (inside $\mathrm{n}^{-}$drift region)

(l) depth of $6.3 \mu \mathrm{m}$ from the $\mathrm{Si}$ surface (inside $\mathrm{n}^{-}$drift region)

(m) depth of $7.3 \mu \mathrm{m}$ from the Si surface (inside $\mathrm{n}^{-}$drift region)

(n) depth of $7.8 \mu \mathrm{m}$ from the Si surface (inside $\mathrm{n}^{-}$drift region)

(o) depth of $8.8 \mu \mathrm{m}$ from the $\mathrm{Si}$ surface (inside $\mathrm{n}^{-}$drift region)

(p) depth of $9.8 \mu \mathrm{m}$ from the $\mathrm{Si}$ surface (inside $\mathrm{n}^{-}$drift region) 


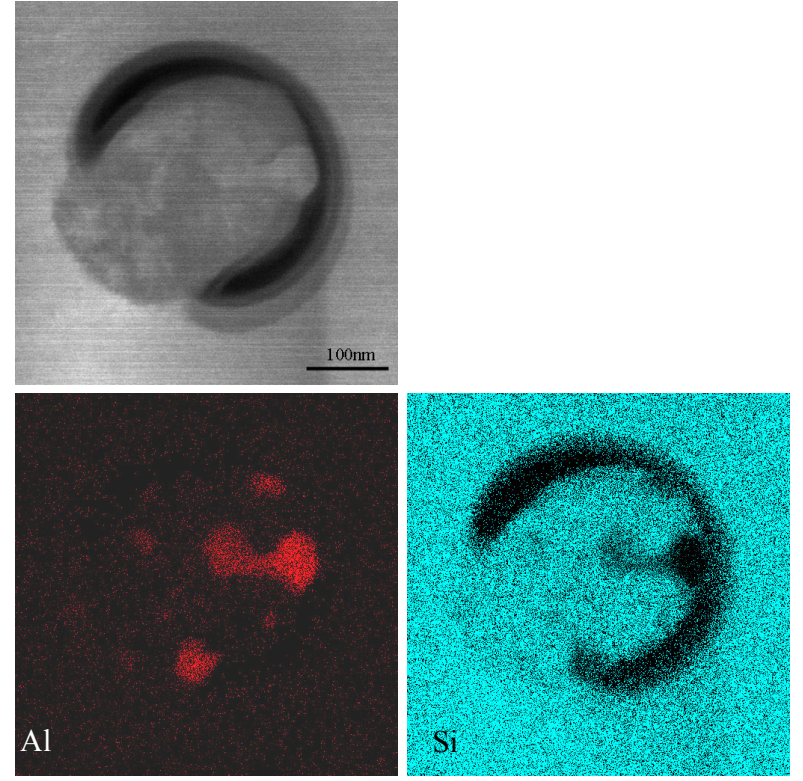

Fig. 8. HAADF-STEM image and EDX elemental maps.

The void shown in Fig. 8 has a diameter of $0.34 \mu \mathrm{m}$, which is smaller than the value of $1 \mu \mathrm{m}$ for the void shown in Fig. 7. Thus, the extent of the SEB damage region is variable. In the HAADF-STEM image, there is a contrast difference between the inside and outside of the annular void. This reflects the melt-solidification that occurred within the damage region due to the highly localized SEB current. Moreover, the Al elemental map shows that $\mathrm{Al}$ atoms have migrated from the anode to the inside of the device.

\section{ESTIMATION OF AREA OF DAMAGE REGION USING THERMAL DIFFUSION EQUATION}

In this section, analytical formulae for the local rise in temperature during SEB were derived from the thermal diffusion equation. The diameter of the circular damage region was estimated using these formulae together with the energy associated with Joule heating, which was determined by TCAD device simulations. This energy is calculated from the time integration of the simulated heat generated, based on the product of the voltage and the SEB current shown in Fig. 3. The first current peak at a time of $1 \times 10^{-12} \mathrm{~s}$ is associated with acceleration of the initially generated electron-hole pairs along the recoil ion track by the electric field in the depletion region. Subsequent current flow is due to current induced avalanche. The temporary decrease in the current just before $1 \times 10^{-9} \mathrm{~s}$ shown in Fig. 3 is caused by a decrease in the impact ionization rate at the $\mathrm{n}^{-} / \mathrm{n}^{+}$interface, when the peak electric field shifts to deep within the $\mathrm{n}^{+}$diffusion region [19] [20]. Finally, the current again increases due to impact ionization deep within the $\mathrm{n}^{+}$diffusion region. The total SEB failure period in Fig. 3 is $2.55 \times 10^{-9} \mathrm{~s}$, and during this period, the thermal diffusion length for $\mathrm{Al}$ is calculated to be $0.5 \mu \mathrm{m}$ using

$$
\sqrt{D_{\mathrm{Al}} \tau}=\sqrt{0.9975 \times 10^{8}\left[\mu \mathrm{m}^{2} / \mathrm{s}\right] \times 2.55 \times 10^{-9}[\mathrm{~s}]}=0.5 \mu \mathrm{m}
$$

Here, $D_{\mathrm{Al}}$ is the thermal diffusion coefficient for $\mathrm{Al}$, and $\tau$ is the diffusion period. Thus, the heat does not propagate to the surface of the 5 - $\mu$ m-thick Al electrode in the short diffusion period of $2.55 \times 10^{-9} \mathrm{~s}$. This is consistent with the device simulation results shown in Figs. 3 and 6(e), which indicate no increase in the $\mathrm{Al}$ surface temperature. It is also in agreement with the SEM images of the Al surface in Fig. 4, where no damage due to SEB is observed. Therefore, the thermal boundary condition can be treated on the device surface as adiabatic boundary. The thermal diffusion equation during SEB is given by

$$
\begin{gathered}
\frac{\partial T(\mathbf{r}, t)}{\partial t}-D_{\mathrm{Si}} \nabla^{2} T(\mathbf{r}, t)=\frac{q(t)}{\rho C_{p}}, \\
q(t)=\frac{P(t)}{\Delta}=\frac{I(t) \cdot V(t)}{\Delta} .
\end{gathered}
$$

Here, $D_{\mathrm{Si}}\left(0.883 \mathrm{~cm}^{2} / \mathrm{s}\right)$ is the thermal diffusion coefficient for $\mathrm{Si}, q(t)$ is the heat generated per unit volume, expressed as the product of the SEB current $I(t)$ and the applied voltage $V(t)$, divided by the heat generation volume $\Delta\left[\mathrm{cm}^{3}\right], \rho\left(2.33 \mathrm{~g} / \mathrm{cm}^{3}\right)$ is the mass density of $\mathrm{Si}$ and $C_{p}(0.69 \mathrm{~J} / \mathrm{gK})$ is the specific heat capacity of $\mathrm{Si}$.

The lattice temperature is expressed as

$$
\begin{aligned}
T(\mathbf{r}, t)=T_{0} & +\frac{1}{\rho C_{p}} \int_{0}^{t} q(\tau) \mathrm{d} \tau \int_{-a / 2}^{a / 2} d x^{\prime} \int_{-b / 2}^{b / 2} d y^{\prime} \int_{-c / 2}^{c / 2} d z^{\prime} \\
& \times \frac{1}{\left[4 \pi D_{\mathrm{Si}}(t-\tau)\right]^{3 / 2}} \cdot \exp \left\{\frac{-\left(x-x^{\prime}\right)^{2}}{4 D_{\mathrm{Si}}(t-\tau)}\right\} \\
& \times \exp \left\{\frac{-\left(y-y^{\prime}\right)^{2}}{4 D_{\mathrm{Si}}(t-\tau)}\right\} \cdot \exp \left\{\frac{-\left(z-z^{\prime}\right)^{2}}{4 D_{\mathrm{Si}}(t-\tau)}\right\} \cdot \text { (4) }
\end{aligned}
$$

where $T_{0}$ is the ambient temperature.

The heat generation volume for the SEB is defined by $\Delta\left(-a / 2 \leq x^{\prime} \leq a / 2,-b / 2 \leq y^{\prime} \leq b / 2,-c / 2 \leq z^{\prime} \leq c / 2\right)$.

The lattice temperature at the center of the heat generation volume is expressed by

$$
\begin{aligned}
T\left(\mathbf{0}, t_{f}\right) \equiv & T\left(t_{f}\right) \\
= & T_{0}+\frac{E}{\rho C_{p} \Delta t_{f}} \int_{0}^{t_{f}} \mathrm{~d} \tau\left[\operatorname{erf}\left(\frac{a}{4 \sqrt{D_{\mathrm{Si}} \tau}}\right)\right] \\
& \times\left[\operatorname{erf}\left(\frac{b}{4 \sqrt{D_{\mathrm{Si}} \tau}}\right)\right] \cdot\left[\operatorname{erf}\left(\frac{c}{4 \sqrt{D_{\mathrm{Si}} \tau}}\right)\right], \\
& E \equiv \int_{0}^{t_{f}} I(\tau) \cdot V(\tau) \mathrm{d} \tau .
\end{aligned}
$$

where $t_{f}[\mathrm{~s}]$ and $E[\mathrm{~J}]$ are respectively the failure period and the energy due to Joule heating associated with the SEB.

The error function erf $(x)$ can be expanded in the following series.

$$
\operatorname{erf}(x)=\frac{2}{\sqrt{\pi}} \sum_{n=0}^{\infty} \frac{(-1)^{n} \cdot x^{2 n+1}}{n !(2 n+1)}
$$

This can be approximated as 


$$
\begin{aligned}
\operatorname{erf}(x) & \left.\approx \frac{2}{\sqrt{\pi}} x \quad \text { if } \quad x \leq \frac{\sqrt{\pi}}{2}\right) . \\
& \approx 1 \quad\left(\text { if } \quad x \geq \frac{\sqrt{\pi}}{2}\right) .
\end{aligned}
$$

For a failure period of $2.55 \times 10^{-9} \mathrm{~s}$, if $\frac{a}{4 \sqrt{D_{\mathrm{Si}} t_{f}}} \geq \frac{\sqrt{\pi}}{2}$, the size of the heat generation region is given by

$$
a \geq \sqrt{4 \pi D_{\mathrm{Si}} t_{f}}=1.68[\mu \mathrm{m}]
$$

Therefore, when $t_{f} \leq t_{a}=\frac{a^{2}}{4 \pi D_{\mathrm{Si}}}$, Eq. (5) can be simplified as

$$
\begin{aligned}
& T\left(t_{f}\right)=T_{0}+\frac{1}{\rho C_{p}} \frac{\int_{0}^{t_{f}} I(\tau) \cdot V(\tau) d \tau}{\Delta} \\
&=T_{0}+\frac{E}{\rho C_{p} \Delta t_{f}} . \\
& \text { if } t_{f} \leq t_{a}=a^{2} / 4 \pi D_{\mathrm{Si}}
\end{aligned}
$$

In contrast, when $\frac{a}{4 \sqrt{D_{\mathrm{Si}} t_{f}}} \leq \frac{\sqrt{\pi}}{2}$, the size of the heat

generation region is

$$
a \leq \sqrt{4 \pi D_{\mathrm{Si}} t_{f}}=1.68[\mu \mathrm{m}] .
$$

The diameters of the damaged region in Fig. 7(b) and Fig. 8 are $1 \mu \mathrm{m}$ and $0.34 \mu \mathrm{m}$, respectively, both of which agree with Eq. (11).

In the case of $t_{a}=t_{b}=\frac{a^{2}}{4 \pi D_{\mathrm{Si}}} \leq t_{f} \leq t_{c}$, Eq. (5) can be simplified using Eq. (8) as follows:

$$
\begin{aligned}
T\left(t_{f}\right)= & T_{0}+\frac{E}{\rho C_{p} \Delta t_{f}} \int_{0}^{t_{f}} \mathrm{~d} \tau\left[\operatorname{erf}\left(\frac{a}{4 \sqrt{D_{\mathrm{Si}}}}\right)\right] \\
& \times\left[\operatorname{erf}\left(\frac{b}{4 \sqrt{D_{\mathrm{Si}} \tau}}\right)\right] \cdot\left[\operatorname{erf}\left(\frac{c}{4 \sqrt{D_{\mathrm{Si}} \tau}}\right)\right] \\
= & T_{0}+\frac{E}{\rho C_{p} \Delta t_{f}} \\
& \times\left\{\int_{0}^{t_{a}} 1 d \tau+\int_{t_{a}}^{t_{f}}\left[\frac{2}{\sqrt{\pi}} \frac{a}{4 \sqrt{D_{\mathrm{Si}} \tau}}\right] \cdot\left[\frac{2}{\sqrt{\pi}} \frac{b}{4 \sqrt{D_{\mathrm{Si}} \tau}}\right] d \tau\right\} \\
= & T_{0}+\frac{E}{\rho C_{p} \Delta} \cdot \frac{t_{a}}{t_{f}}\left\{1+\log \left(\frac{t_{f}}{t_{a}}\right)\right\} \\
& \text { if } t_{a}=t_{b}=\frac{a^{2}}{4 \pi D_{S i}} \leq t_{f} \leq t_{c}
\end{aligned}
$$

The size of the damage region was then estimated using Eq. (12) and the simulated energy E, which was calculated to be $3.57 \times 10^{-7} \mathrm{~J}$ by integrating the product of the voltage and the SEB current shown in Fig. 3 from 0 to $2.55 \times 10^{-9} \mathrm{~s}$. In addition, the potential distribution adopts a funnel-like shape during the
SEB [19] [20]. The heat generation depth $\mathrm{c}$ is $150 \mu \mathrm{m}$ in light of the potential deformation during the SEB shown in Fig. 9. Finally, the temperature $T\left(t_{f}\right)$ reaches the melting point of $\mathrm{Si}$ $(1683 \mathrm{~K})$ after $2.55 \times 10^{-9} \mathrm{~s}$, as shown in Fig. 3. By substituting $E$ $=3.57 \times 10^{-7} \mathrm{~J}, t_{f}=2.55 \times 10^{-9} \mathrm{~s}, T\left(t_{f}\right)=1683 \mathrm{~K}$ and $\mathrm{T} 0=300 \mathrm{~K}$ into Eq. (12), we obtain an a value of $0.406 \mu \mathrm{m}$, which is the same order of magnitude as the values of $1 \mu \mathrm{m}$ and $0.34 \mu \mathrm{m}$ in Fig. 7(b) and Fig. 8, respectively. The amount of initially generated charge due to recoil ions varies stochastically, and affects the size of the SEB damage region.

Fig. 10 shows the simulated SEB current, and the maximum electron and hole current density determined by TCAD simulations. The maximum current density for both electrons and holes is on the order of $10^{7} \mathrm{~A} / \mathrm{cm}^{2}$. On the other hand, based on a maximum SEB current of $0.15 \mathrm{~A}$ and a Joule heating area of $\pi a^{2}=\pi(0.406 \mu \mathrm{m})^{2}$, the maximum SEB current density is estimated to be $2.9 \times 10^{7} \mathrm{~A} / \mathrm{cm}^{2}$, which is similar to the simulated current density shown in Fig. 10. Furthermore, the estimated current density $2.9 \times 10^{7} \mathrm{~A} / \mathrm{cm}^{2}$ corresponds to the positive differential resistance (PDR) region shown in Fig. 11. These results support the validity of the proposed mechanism, by which SEB in power diodes occurs by thermal failure caused by local secondary breakdown.

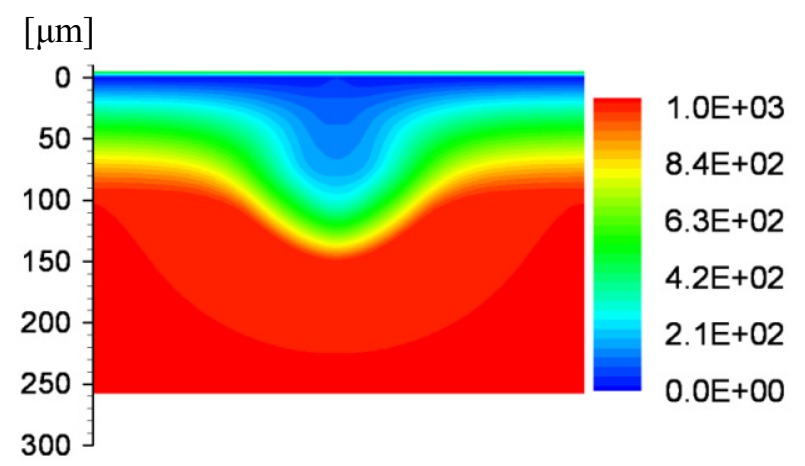

Fig. 9. Electrostatic potential [V] at the times $2.55 \times 10^{-9} \mathrm{~s}$ shown in Fig. 3.

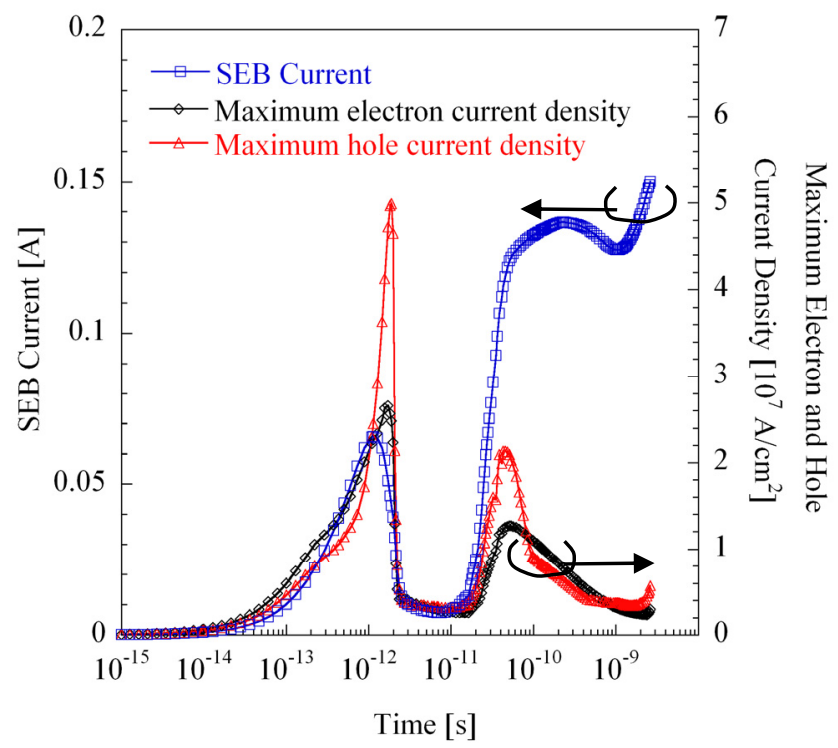

Fig. 10. Simulated SEB current, and maximum electron and hole current density. 


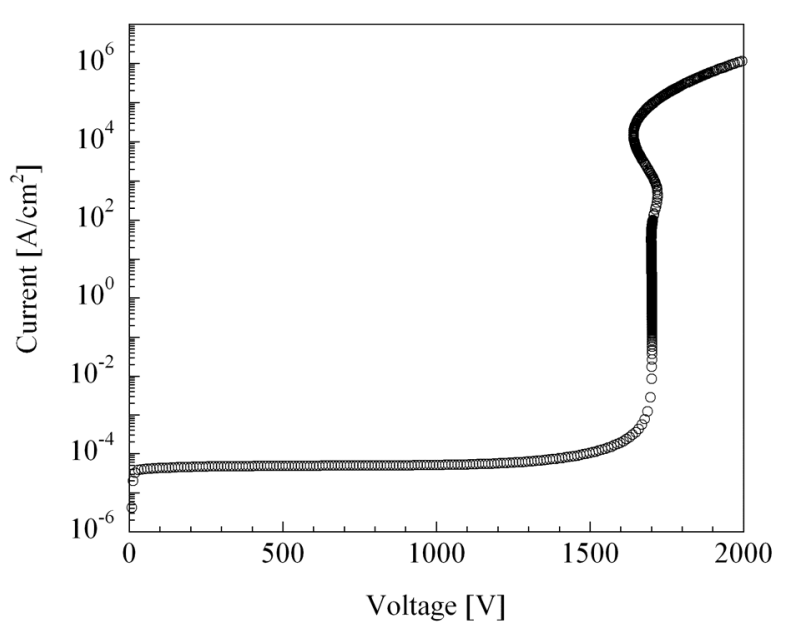

Fig. 11. Simulated static characteristic of power diode.

\section{CONCLUSION}

An analysis of neutron-induced SEB in Si power diodes has been carried out using a slice-and-view imaging technique. Unique annular microvoids were observed inside the devices, whose axially symmetric shape reflects spatially isotropic thermal diffusion. Analytical formulae for the local rise in temperature during SEB were derived from the thermal diffusion equation. The diameter of the damage region was theoretically estimated using these formulae together with the energy associated with Joule heating, which was calculated by TCAD device simulations. The estimated diameter of the damage region was similar to the observed sizes of the annular voids. Based on this diameter, the current density during SEB was calculated to be $2.9 \times 10^{7} \mathrm{~A} / \mathrm{cm}^{2}$. This high current density corresponds to the positive differential resistance (PDR) region associated with secondary breakdown of the diodes. This holds for diode structures where the peak electric field can shift deep into the $\mathrm{n}^{+}$diffusion region, if this region has doping density which is of a not too steep gradient $\mathrm{dn} / \mathrm{dx}$. These results support the proposed mechanism by which SEB in power diodes occurs due to thermal failure caused by local secondary breakdown.

\section{REFERENCES}

[1] J.F. Ziegler, "Terrestrial cosmic rays," IBM J. Research Development, Vol. 40, No.1, 1996, pp.19 - 39.

[2] W. Kaindl, G. Soelkner, H. J. Schulze, and G. Wachutka, "Cosmic radiation-induced failure mechanism of high voltage IGBT," in Proc. Int. Symp. Power Semiconductor Device and ICs, 2005, p. 199 - 202.

[3] D. L. Oberg, J. L. Wert, E. Normand, P. P. Majewski, and S. A. Wender, "First observations of power MOSFET burnout with high energy neutrons," IEEE Trans. Nucl. Sci., Vol.43, 1996, pp. 2914- 2920.

[4] E. Normand, J. L. Wert, D. L. Oberg, P. R. Majewski, P. Voss, and S. A. Wender, "Neutron-induced single event burnout in high voltage electronics," IEEE Trans. Nucl. Sci., Vol. 44, 1997, pp. 2358 - 2366.

[5] H. Zeller, "Cosmic ray induced failures in high power semiconductor devices," Solid-State Electron., Vol. 38, 1995, pp. 2041-2046.

[6] T. F. Wrobel and D. E. Beutler, "Solutions to heavy ion induced avalanche burnout in power devices," IEEE Trans. Nucl. Sci., Vol. 39, 1992, pp. $1636-1641$.

[7] G. H. Johnson, J. H. Hohl, R. D. Schrimpf, and K. F. Galloway, "Simulating single-event burnout of n-channel power MOSFET's," IEEE Trans. Electron Devices, Vol. 40, 1993, pp. 1001 - 1008.

[8] F. Roubaud, C. Dachs, J.-M. Palau, J. Gasiot, and P. Tastet, "Experimental and 2D simulation study of the single-event burnout in
N-channel power MOSFETs," IEEE Trans. Nucl. Sci., Vol. 40, 1993, pp. $1952-1958$.

[9] C. Dachs, F. Roubaud, J.-M. Palau, G. Bruguier, J. Gasiot, P. Tastet, M.-C. Calvett, and P. Calve, "Simulation aided hardening of N-channel power MOSFETs to prevent single event burnout," IEEE Trans. Nucl. Sci., Vol.42, 1995, pp. 1935 - 1939.

[10] G. H. Johnson, J. M. Palau, C. Dachs, K. F. Galloway, and R. D. Schrimpf, "A review of the techniques used for modeling single-event effects in power MOSFETs," IEEE Trans. Nucl. Sci., Vol. 43, 1996, pp. 546 - 560.

[11] M. Allenspach, C. Dachs, G. H. Johnson, R. D. Schrimpf, E. Lorfevre, J. M. Palau, J. R. Brews, K. F. Galloway, J. L. Titus, and C. F. Wheatley, "SEGR and SEB in n-channel power MOSFETs," IEEE Trans. Nucl. Sci., Vol. 43, 1996, pp. 2927 - 2931.

[12] E. Dodd, "Physics-based simulation of single-event effects," IEEE Trans. Device Mater. Reliab., Vol. 5, 2005 pp. 344- 357.

[13] G. Busatto, A. Porzio, F. Velardi, F. Iannuzzo, A. Sanseverino, and G. Currò, "Experimental and Numerical investigation about SEB/SEGR of Power MOSFET," Microelectron. Reliab., Vol. 45, 2005, pp. 1711-1716.

[14] S. Liu, M. Boden, D. A. Girdhar, and J. L. Titus, "Single-Event Burnout and Avalanche Characteristics of Power DMOSFETs," IEEE Trans. Nucl. Sci., Vol. 53, 2006, pp. 3379 - 3385.

[15] S. Liu, J. L. Titus, and M. Boden, "Effect of Buffer Layer on Single-Event Burnout of Power DMOSFETs," IEEE Trans. Nucl. Sci., Vol. 54, 2007, pp. $2554-2560$.

[16] T. Shoji, S. Nishida, T. Ohnishi, T. Fujikawa, N. Nose, M. Ishiko, and K. Hamada, "Neutron induced single-event burnout of IGBT," Int. Power Electronics Conf., 2010, pp. 142 - 148.

[17] S. Nishida, T. Shoji, T. Ohnishi, T. Fujikawa, N. Nose, M. Ishiko, and K. Hamada, "Cosmic ray ruggedness of IGBTs for hybrid vehicles," Int. Symp. Power Semiconductor Devices and ICs, 2010, pp. 129 - 132.

[18] T. Shoji, S. Nishida, T. Ohnishi, T. Fujikawa, N. Nose, K. Hamada, and M. Ishiko, "Reliability Design for Neutron Induced Single-Event Burnout of IGBT,” IEEJ Trans. Ind. Appl., Vol. 131, 2011, pp. 992-999.

[19] T. Shoji, S. Nishida, and K. Hamada, "Triggering Mechanism for Neutron Induced Single Event Burnout in Power Diode," 2012 Int. Conf. on Solid State Devices and Materials, 2012, pp.1235-1236.

[20] T. Shoji, S. Nishida, and K. Hamada, "Triggering Mechanism for Neutron Induced Single Event Burnout in Power Devices," Jpn. J. Appl. Phys., Vol. 52, 2013, 04CP06-1. [Errata; 52 2013, 129201]

[21] T. Shoji, S. Nishida, K. Hamada, and H. Tadano, "Neutron Induced Single-Event Burnout in SiC Power Diode," 2013 International Conference on Solid State Devices and Materials, 2013, pp. 954-955

[22] T. Shoji, S. Nishida, K. Hamada, and H. Tadano, "Experimental and simulation studies of neutron-induced single-event burnout in $\mathrm{SiC}$ power diodes," Jpn. J. Appl. Phys., Vol. 53, 2014, 04EP03

[23] Pfirsch, F. ; Infineon Technol. AG, Neubiberg, Germany ; Soelkner, G., "Simulation of cosmic ray failures rates using semiempirical models" in Proc. Int. Symp. Power Semiconductor Device and ICs, 2010, p. 125 128

[24] Weiss, C., Wachutka, G. ; Hartl, A. ; Hille, F. ; Pfirsch, F., "Predictive physical model of cosmic-radiation-induced failures of power devices", Power Electronics and Motion Control Conference (EPE/PEMC), 2012, LS2e.3-1 - LS2e.3-5

[25] Hiroaki Asai, , Kenji Sugimoto, Isamu Nashiyama, Yoshiya Iide, Kensuke Shiba, Mieko Matsuda, and Yoshio Miyazaki "Terrestrial Neutron-Induced Single-Event Burnout in SiC Power Diodes", IEEE Trans. Nucl. Sci., 2012 59, pp. 880 - 885.

[26] H. Egawa, "Avalanche characteristics and failure mechanism of high voltage diodes", IEEE Trans. Electron Devices, 1996 13, pp. 754 -758

[27] Josef Lutz, Roman Baburske, Min Chen, Birk Heinze, Martin Domeij, Hans-Peter Felsl, and Hans-Joachim Schulze, "The $n^{+}-J u n c t i o n$ as the Key to Improved Ruggedness and Soft Recovery of Power Diodes, IEEE Trans. Electron Devices, 200956 pp. 2825 - 2832

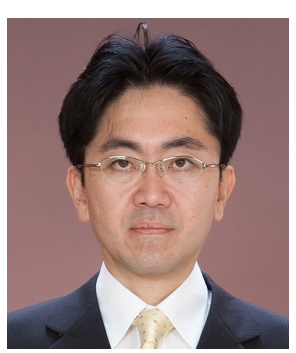

Tomoyuki Shoji received his M.S. degree in Physics from Ritsumeikan University, Kyoto, Japan in 1993. He joined Toyota Central R\&D Labs., Inc. in 2001. He is currently pursuing his $\mathrm{Ph} . \mathrm{D}$. degree at the graduate school of pure and applied sciences at The University of Tsukuba. His current research interests include design, development, and reliability physics of power devices and 
modules, using electro thermal device simulation and 3D thermal stress simulation. He is a member of the Japan Society of Applied Physics (JSAP) and the Institute of Electrical Engineering of Japan (IEEJ). He received IEEJ Distinguished Paper Award from the Institute of Electrical Engineers of Japan in 2014.

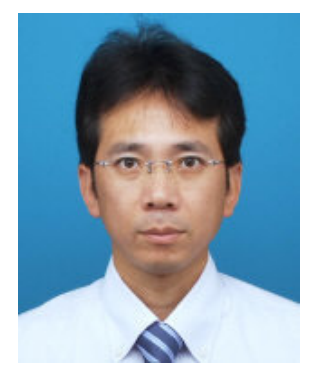

Shuichi Nishida received his M.E. degree in Material Science and Engineering from Nagoya Institute of Technology, Japan in 1994. He joined Toyota Motor Corporation in 2001. His current research interests are reliability technology and analysis technology for power semiconductor devices. He is a member of the Institute of Electrical Engineering of Japan (IEEJ). He received IEEJ Distinguished Paper Award from the Institute of Electrical Engineers of Japan in 2014.

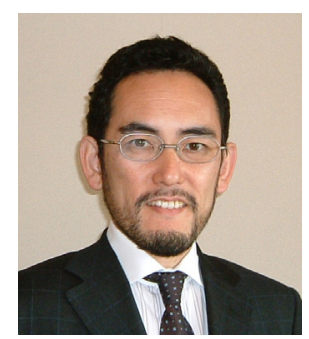

Kimimori Hamada received his M.E. degree in Electrical Engineering from Osaka Prefecture University, Japan in 1985 . He joined Toyota Motor Corporation in 1985. He was involved in the in-house semiconductor project in TMC as one of the founding members in 1987. He has been involved in process development for lithography and wet etching technologies for semiconductors, and power MOSFET, BiCDMOS and IGBT device development. He is currently the project general manager of Electronics Development Division 3 with responsibility for the development of in-house semiconductors, such as BiCDMOS, IGBT, $\mathrm{SiC}$ and $\mathrm{GaN}$. He is a member of the Institute of Electrical Engineers of Japan (IEEJ) and the Society of Automotive Engineers of Japan (JSAE). He is a member of the "Research Committee on Power Devices and ICs" in IEEJ and a general chair of "Technical Committee of Automotive Power Electronics" in JSAE. He participates in the committees of some international conferences related to power semiconductors and power electronics such as ISPSD, IPEC Niigata, PCC- Nagoya, APE and CIPS2014. He received the Best Paper Award of ISPSD2005 and IEEJ Distinguished Paper Award from the Institute of Electrical Engineers of Japan in 2014.

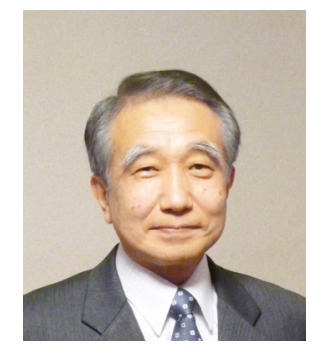

Hiroshi Tadano (M'80) received his Ph.D. degree in semiconductor technology from Tohoku University in 1980. In 1980, he joined Toyota Central R\&D Labs, Inc., where he engaged in the research and development of power devices such as SIT, IGBT, diodes and power MOSFETs.

Since 2013 he has been a professor at The Graduate School of Pure and Applied Science at The University of Tsukuba. His current research interest is high-efficiency power conversion circuits for electric vehicles using advanced power devices.

$\mathrm{He}$ is a member of the IEEE, the Institute of Electrical Engineering of Japan (IEEJ), the Institute of Electronics, Information and Communication Engineers (IEICE) and the Japan Institute of Power Electronics (JIPE). 